\title{
INHIBITORY OF $\alpha$-GLUCOSIDASE AND MOLECULAR DOCKING OF WHITE TEA POLYPHENOL (Camellia sinensis): COMPARISON OF SEVERAL SOLVENT MODIFICATIONS AND CHEMOMETRICS APPROACH
}

\author{
Shaum Shiyan ${ }^{1, *}$, Fitrya $^{1}$, Arimia $^{1}$ and Galih Pratiwi ${ }^{2, *}$ \\ ${ }^{1}$ Department of Pharmacy, Faculty of Mathematics and Natural Sciences, Universitas Sriwijaya, \\ Indralaya (OI) Sumatera Selatan Indonesia, 30662 \\ ${ }^{2}$ Department of Pharmacy, STIKES Aisyiyah Palembang, Sumatera Selatan Indonesia, 30152 \\ *E-mail: shaumshiyan@unsri.ac.id, galihpratiwi.apt@gmail.com
}

\begin{abstract}
Diabetes type 2 is a metabolic disease with an increasing prevalence. White tea is produced from Camellia sinensis L. Kuntze, has a high content of phenolic compounds, and has the potential to inhibit the enzyme $\alpha$-glucosidase. The study was designed to study variations of solvent modification on total phenolic content (TPC) levels, total flavonoid content (TFC), and in vitro inhibitory effects. Modification of solvents as independent variables includes cold water, hot water, ethanol, cold citric acid, and hot citric acid. Ethanol solvent has the highest TPC and TFC content. Cold citric acid can increase TPC, TFC, and $\alpha$-glucosidase inhibition compared to cold water. The smallest $\alpha$-glucosidase $\mathrm{IC}_{50}$ value was found in ethanol solvent followed by cold citric acid. Principle component analysis (PCA) and cluster analysis (CA) indicated that ethanol and cold citric acid solvents had the highest similarity, and the TPC response was negatively correlated with $\mathrm{IC}_{50} \alpha$-glucosidase. In silico studies using molecular docking, the approach showed a strong bond between the catechins and the $\alpha$-glucosidase active site. In conclusion, the type of solvent in the extraction process affects TPC, TFC, and IC50 $\alpha$-glucosidase. Modifying acid solvents in the extraction of white tea can be considered a potential opportunity for further development

Keywords: Camellia sinensis, White Tea, Catechin, $\alpha$-Glucosidase, Chemometrics, PCA-CA
\end{abstract}

(C) RASĀYAN. All rights reserved

\section{INTRODUCTION}

Diabetes is a metabolic disease of concern and a hot issue because of its increasing prevalence. Lifestyle and prevalence in diabetes type 2 are of concern in the health sector, especially pharmacy. One of the targets in diabetes therapy is by inhibiting the breakdown of carbohydrates after eating (postprandial) ${ }^{1,2}$ The $\alpha$-glucosidase enzyme plays an essential role in breaking down polysaccharides and disaccharides into glucose. ${ }^{3}$ The condition of hyperglycemia will appear and get worse if glucose in blood vessels cannot be transferred into cells due to insulin resistance. Therefore, an $\alpha$-glucosidase inhibiting agent is needed to treat hyperglycemia after eating. One of the $\alpha$-glucosidase inhibitors is acarbose, but its use causes side effects such as flatulence, diarrhea, pain, and jaundice, and hepatitis. ${ }^{1,3,4}$ As an alternative, supportive therapy can be given using natural products.

Tea leaf (Camellia sinensis) has potential as an $\alpha$-glucosidase inhibitor. Scientifically proven black tea and green tea can inhibit $\alpha$-glucosidase in the intestine, and the active compound responsible is catechins. ${ }^{3,5}$ A single catechin compound can inhibit the activity of the $\alpha$-glucosidase enzyme and potentially as an antidiabetic. ${ }^{6}$ White tea has advantages over black tea and green tea products, including higher catechin derivative content, and has potent antioxidant activities. ${ }^{7,8,9}$ Phenolic and polyphenol compounds can counteract free radicals to have a protective effect on pancreatic $\beta$ cells. ${ }^{10}$ The strength of pharmacological activity depends on the composition and amount of the active compound content. In daily life, people brew tea with hot water, and at an industrial level, organic solvents such as ethanol can

Rasayan J. Chem., 13(3), 1472-1477(2020)

http://dx.doi.org/10.31788/ RJC.2020.1335755

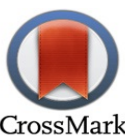


RASĀYAN J. Chem.

Vol. 13 | No. 3 |1472-1477| July - September | 2020

be used. Therefore, an understanding of variations in the solvent modification is needed for the characteristics of active components and pharmacological effects.

Some processes of extracting phenolic compounds on tea leaves, namely extraction using hot water at a temperature of $95^{\circ} \mathrm{C}$, cold steeping with a temperature of $25^{\circ} \mathrm{C}$ for 2 hours, extraction using ethanol and modification of solvents using citric acid. ${ }^{8-11}$ Each process has different results on the phenolic compounds obtained. However, related to testing as an $\alpha$-glucosidase inhibitor, there is no comprehensive explanation of the comparison and its correlation. Therefore, it is exciting to explore variations of solvents and extraction techniques on the activity of $\alpha$-glucosidase inhibitors. Chemometrics approaches using principal component analysis-cluster analysis (PCA-CA) methods help classify and evaluate correlations between responses. The in silico assay using the molecular docking approach can also explain the mechanism of action of $\alpha$-glucosidase inhibitors.

\section{EXPERIMENTAL}

\section{Chemicals and Reagents}

Chemicals such as the $\alpha$-glucosidase, bovine serum albumin (BSA), p-nitrophenyl- $\alpha$-D-glucopyranoside (PNPG) substrate were procured from Sigma-Aldrich (St. Louis, MO, USA). Dimethylsulfoxide (DMSO), folin ciocalteu reagent, aluminum chloride, methanol, ethanol, and potassium dihydrogen phosphate were purchased from Merck (Darmstadt, Germany), and distilled water was obtained from Brataco (Jakarta, Indonesia). White tea products were purchased from the Gamboeng (Ciwidey, Jawa Barat, Indonesia).

\section{White Tea Sample Preparation}

Cold steeping is prepared by brewing $200 \mathrm{mg}$ of white tea in $20 \mathrm{~mL}$ of distilled water at $20-25^{\circ} \mathrm{C}$, carried out for 2 hours, and hot steeping is prepared at a temperature of $95^{\circ} \mathrm{C}$ for 9 minutes. ${ }^{8}$ Ethanol extract is obtained by entering $200 \mathrm{mg}$ of white tea in $20 \mathrm{~mL} 96 \%$ ethanol and maceration for 30 minutes. ${ }^{9}$ Brewing using a modified acid solvent from the existing procedure with $200 \mathrm{mg}$ powder and $20 \mathrm{~mL}$ solvent. ${ }^{11}$

\section{Determination of Total Phenolic Content (TPC)}

The measurement procedure follows an existing protocol with gallic acid as the standard for making calibration curves and the Folin Ciocalteu reagent as the primary reagent in the determination of TPC. ${ }^{12}$ Absorbance was measured using Genesys 10S spectrophotometer instrumentation (Thermo Scientific, USA) at $752 \mathrm{~nm}$. TPC calculation results are expressed in $\mathrm{mg}$ GAE/g using a linear equation from the calibration curve. ${ }^{13}$

\section{Determination of Total Flavonoid Content (TFC)}

Total flavonoid content (TFC) measure by using a protocol that has been established with the chemical compound catechin as a standard. ${ }^{7,14}$ Reagents used include aluminum chloride $(2 \%$, w/v), sodium nitrite $(5 \%, \mathrm{w} / \mathrm{v})$, and sodium hydroxide. The reacted samples were measured at a wavelength of $510 \mathrm{~nm}$ using a UV-Vis spectrophotometer.

\section{In Vitro Inhibition of $\alpha$-Glucosidase Activity}

Measurement of $\alpha$-glucosidase activity follows the available procedure with a few modifications. Blank solution and blank control use $10 \mu \mathrm{L}$ DMSO. Testing the sample and control sample using $10 \mu \mathrm{L}$ white tea and acarbose samples. The solution of each sample was added with $55 \mu \mathrm{L}$ phosphate buffer $\mathrm{pH} 6.8$ and $10 \mathrm{mM}$ PNPG substrate in the amount of $10 \mu \mathrm{L}$, incubated for 5 minutes at $37^{\circ} \mathrm{C}$. The test was continued by adding $100 \mu \mathrm{L}$ of $200 \mathrm{mM}$ sodium carbonate and re-incubation for 30 minutes at $37^{\circ} \mathrm{C}$. After incubation, $25 \mu \mathrm{L}$ of $0.05 \mathrm{U} / \mathrm{mL}$ of enzyme solution was added, and absorbance was measured at $405 \mathrm{~nm}$.

\section{In Silico with the Molecular Docking Approach}

Molecular interactions between the $\alpha$-glucosidase enzyme and dominant compounds in white tea (catechin derivate) samples were analyzed using the help of Molecular Operating Environment (MOE) 
RASĀYAN J. Chem.

Vol. 13 | No. 3 |1472-1477| July - September | 2020

software (Chemical Computing Group, Montreal, Canada). This analysis aims to see the interaction between the chemical structure of $\alpha$-glucosidase and the substrate in the form of catechin and acarbose compounds. The main parameters analyzed included bond profiles, pharmacophores of the substrate, bond distance, and strength.

\section{Statistical Analysis}

Simple statistical analysis using SPSS software (SPSS Inc., Chicago, IL, USA) with a significance level of 0.05. Multivariate analysis using a chemometric approach with PCA-CA techniques using Minitab software (Minitab, State College, PA, USA).

\section{TPC and TFC Levels on Various Solvent Modifications}

\section{RESULTS AND DISCUSSION}

Total phenolic for each sample as follows, hot water was $69.86 \mathrm{mg} \mathrm{GAE} / \mathrm{g}$, cold water was $112.87 \mathrm{mg}$ GAE/g, and ethanol was $155.22 \mathrm{mg} \mathrm{GAE} / \mathrm{g}$ sample. A comparison of each steeping is presented in Fig.-1. The TPC value in hot steeping with the same procedure is higher than that of other studies, namely 60.01 $\mathrm{mg} \mathrm{GAE} / \mathrm{g}$ sample. The difference in the value obtained is due to differences in the search process. White tea with a powder form has a higher phenolic content than the original form (rolled buds). In the original form, the extraction process is not optimal, so that the content of secondary metabolites is challenging to be dissolved by the solvent.
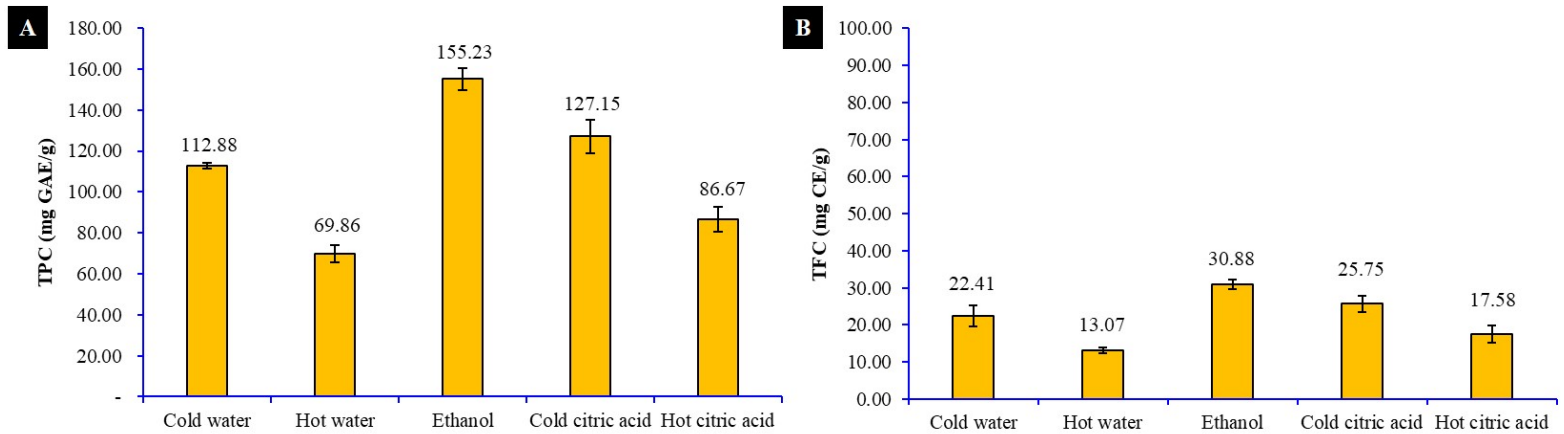

Fig.-1: Levels of TPC (A), and TFC (B) on Various Solvent Modifications

Based on Fig.-1, it can be seen that ethanol extract contains a higher phenolic than cold steeping and hot steeping. Ethanol has a polar hydroxyl group and an aliphatic chain that tends to be non-polar, so it can penetrate cells better than water, which is more polar. Ethanol can increase the permeability of the powder cell wall. These conditions can increase efficiency in attracting phenolic compounds compared to water. Therefore, the use of ethanol solvent in extraction will get a higher total phenolic.

The extraction of phenolic compounds using cold water is better than hot water. This difference is possible because the extraction process's effectiveness in cold water with a longer time allows the compound to diffuse maximally into the solvent. Increased extraction time can increase the migration of compounds so that more and more compounds will dissolve. The use of hot water can change phenol compounds' physical and chemical properties so that instability is possible. ${ }^{8,15}$ Acidic solvents using citric acid have higher TPC and TFC compared to ordinary water solvents. These results are in line with existing theories that acidic properties can provide better stability in catechin derivate compounds. ${ }^{11}$

\section{Inhibition of $\alpha$-Glucosidase Activity}

Based on the total phenolic values, it can be seen that there are differences in the effectiveness of the phenolic compound extraction process between treatments of phenolic content. This difference was also seen using statistical analysis found that the data were normally distributed and homogeneous with a significance level of $0.93(p<0.05)$. The analysis continued with the one way ANOVA test to see significant differences between the six types of solvents, and the results showed that a significance value 
RASĀYAN J. Chem.

Vol. 13 | No. 3 |1472-1477| July - September | 2020

of $0.00(p<0.05)$. These results indicate significant differences in phenolic levels due to different types of solvents.

Table-1: $\mathrm{IC}_{50}$ Value of the Test Sample

\begin{tabular}{c|c}
\hline Solvent Modification & $\mathrm{IC}_{50}$ Inhibition of $\alpha$-glucosidase \\
\hline Cold water & 28.23 \\
\hline Hot water & 37.88 \\
\hline Ethanol & 18.17 \\
\hline Cold citric acid & 24.52 \\
\hline Hot citric acid & 35.65 \\
\hline Acarbose & 208.72 \\
\hline
\end{tabular}

Based on Table-1, ethanol extract has the smallest $\mathrm{IC}_{50}$ value of $18.17 \mathrm{ppm}$, and this shows that ethanol extract has the most excellent inhibition ability compared to cold and hot steeping. This result correlates with the most significant total phenolic yield found in ethanol extract compared to cold and hot steeping. Phenolic content in white tea is responsible for inhibiting enzyme $\alpha$-glucosidase, especially the active substance catechins.
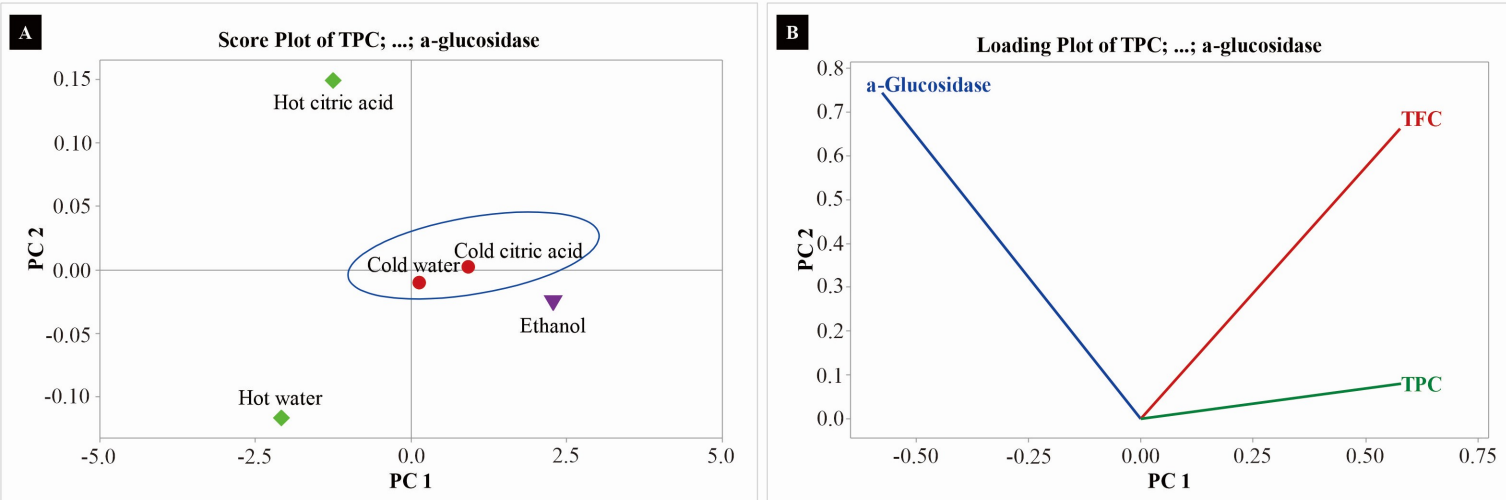

Fig.-2: The Results of the Analysis using PCA Techniques, Score Plot (A), and Loading Plot (B)

The independent variables and the overall response were further analyzed using a chemometric approach with PCA and CA analysis techniques. The analysis results are shown in Fig.-2 and Fig.-3, the score plot in Fig.-2A classifies the solvent modification based on the level of similarity of traits and characters. The nature and characteristics of the cold water and cold citric acid solvents are similar. When compared with ethanol, the similarity of properties is not too different. Inhibiting the activity of the $\alpha$-glucosidase enzyme has been widely explained in the literature. Phenolic compounds have activity as inhibitors of the $\alpha$-glucosidase enzyme, one of which is by influencing the conformation of the active site of the enzyme. ${ }^{3,5,16}$

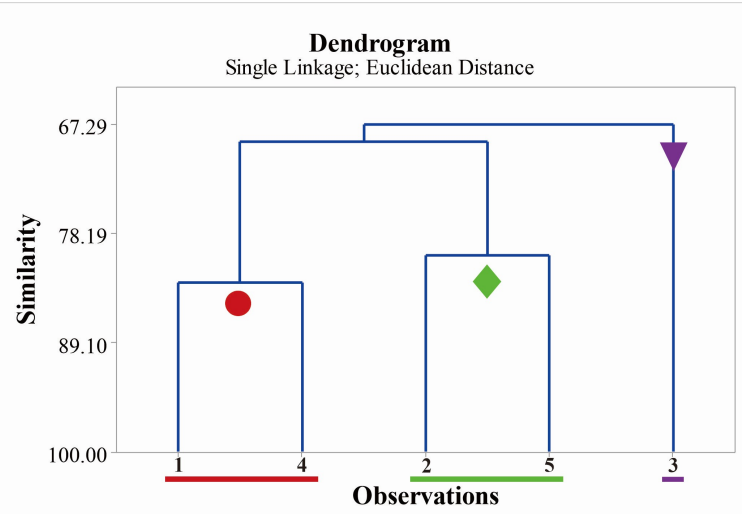

Fig.-3: A Dendrogram Describing the Character Layout of the Response, (1) Cold water, (2) Hot Water, (3) Ethanol, (4) Cold Citric Acid, (5) Hot Citric Acid 
RASĀYAN J. Chem.

Vol. 13 | No. 3 |1472-1477| July - September | 2020

\section{Molecular Docking}

Based on the docking results, the active site of the enzyme is shown in Fig.-4 with green visualization that marks the hydrophobic bond. The pink visualization marks the hydrogen bond. At the same time, the blue color indicates the polar bond. The active site of the $\alpha$-glucosidase enzyme consists of various amino acids that can interact with pharmacophores in the ligand, namely polyphenol compounds in the form of catechins as $\alpha$-glucosidase inhibitors. Phenolic compounds found in white tea in the form of catechins and used as the main pharmacophore. Amino acids that interact with pharmacophores, namely Arg411, Asn61, and Asn58, as shown in Fig.-4C dan Fig.-4F.
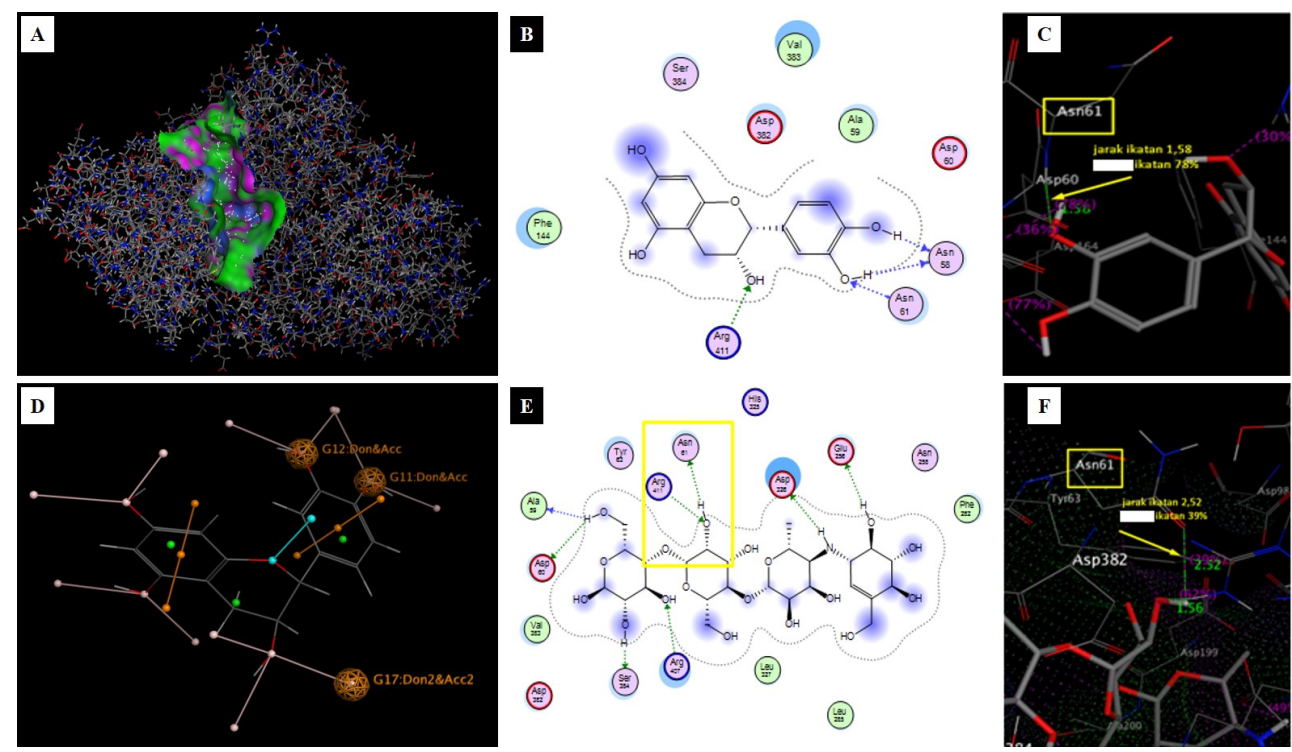

Fig. 4: Molecular Docking of Catechin with $\alpha$-Glucosidase

Based on Fig.-4C and 4F, it can be seen that the amino acids Asn58, Asn61, and Arg411 interact with the pharmacophore groups on catechins (hydroxy groups) on the $\mathrm{B}$ and 3-OH rings on the $\mathrm{C}$ ring which can be seen on Fig.-4D. The pharmacophores of the hydroxy group in ring B act as donors and acceptors whose bonds occur in the primary group marked by don and acc. The 3-OH function group on ring $\mathrm{C}$ acts as don 2 and acc2, which acts as a donor and acceptor whose bonds are located on branches, as shown in Fig.-4D. The results obtained following the theory that the group that plays a role in inhibiting the activity of the $\alpha$-glucosidase enzyme is the hydroxy group on ring B and 3-OH on ring C. ${ }^{17}$

Chemical bonds that occur based on Fig.-4B on the hydroxy group on ring B, namely hydrogen bonds and shaded blue circle marks the bond of contact at the receptor (receptor contact). The bond that occurs in the C-ring 3-OH group marked with a dark blue circle indicates ligand exposure, which means the ligand's place is bound. Hydroxy groups in ring B play a role in interaction with the active site of the enzyme $\alpha$-glucosidase, while the $3-\mathrm{OH}$ group in ring $\mathrm{C}$ functions to maintain the proper binding of flavonoid molecules. ${ }^{17}$

Docking modeling was also carried out on acarbose as an $\alpha$-glucosidase inhibitor. The docking results between the active site of the enzyme and the acarbose can be seen in Fig.-4E. Pharmacophores in the acarbose interact with the same amino acids as catechins, Arg411, and Asn61. In Fig.-4E, it can be seen that Arg411 and Asn61 bind to the same $\mathrm{OH}$ group with multiple roles as acceptors and donors. Situations such as those modeled can weaken the bond between the root and the active site of the enzyme. Compared with catechins that bind more than one group in the enzyme, it causes stronger bonds so that the inhibitory effect will be better.

\section{CONCLUSION}

There is a difference in the effectiveness of the solvent as an inhibitor of the $\alpha$-glucosidase enzyme. Ethanol has the most significant inhibitory activity, followed by the modification of cold citric acid 
RASĀYAN J. Chem.

Vol. 13 | No. 3 |1472-1477| July - September | 2020

solvents. The type of solvent affects the response of TPC, TFC, and $\mathrm{IC}_{50} \alpha$-glucosidase measured. Molecular interactions between enzymes-catechins have differences with enzymes-acarbose. The choice of acid solvents in the extraction of white tea can be developed in extraction technology.

\section{ACKNOWLEDGMENT}

The authors thanks the Department of Pharmacy Faculty of Mathematics and Natural Sciences Universitas Sriwijaya and Department of Pharmacy STIKES 'Aisyiyah Palembang for the facilities.

\section{REFERENCES}

1. K. R. R. Rengasamy, M. A. Aderogba, S. O. Amoo, W. A. Stirk and J. Van Staden, Food Chemistry, 141, 1412(2013), DOI: 10.1016/j.foodchem.2013.04.019.

2. R. Wahyuningrum, D. Wahyono, M. Mustofa and Y. S. Prabandari, Asian Journal of Pharmaceutical and Clinical Research, 10, 246(2017), DOI: 10.22159/ajpcr.2017.v10i7.18217.

3. T. Satoh, M. Igarashi, S. Yamada, N. Takahashi and K. Watanabe, Journal of Ethnopharmacology, 161, 147(2015), DOI: 10.1016/j.jep.2014.12.009.

4. E. Y. Sukandar, A. Retnosari, I. S. Joseph, I. K. Adnyana, A. A. P. Setiadi and Kusnandar, ISO Farmakoterapi, ISFI Penerbitan, Jakarta, Indonesia, 2014.

5. R. Goh, J. Gao, V. K. Ananingsih, V. Ranawana, C. J. Henry and W. Zhou, Food Chemistry, 180, 203(2015), DOI: 10.1016/j.foodchem.2015.02.054.

6. C. Wan, T. Yuan, A. L. Cirello and N. P. Seeram, Food Chemistry, 135, 1929(2012), DOI: 10.1016/j.foodchem.2012.06.056.

7. S. Shiyan, T. Hertiani, R. Martien and A. K. Nugroho, Rasayan Journal of Chemistry, 12, 1098(2019), DOI: 10.31788/RJC.2019.1235276.

8. E. Damiani, T. Bacchetti, L. Padella, L. Tiano and P. Carloni, Journal of Food Composition and Analysis, 33, 59(2014), DOI: 10.1016/j.jfca.2013.09.010.

9. A. A. F. Zielinski, C. W. I. Haminiuk and T. Beta, LWT - Food Science and Technology, 65, 897(2016), DOI: 10.1016/j.1wt.2015.09.020.

10. T. R. Dias, G. Tomás, N. F. Teixeira, M. G. Alves, P. F. Oliveira and B. M. Silva, International Journal of Food Science, Nutrition and Dietetics, 2, 19(2013), DOI: 10.19070/2326-3350-130005.

11. B. F. Zimmermann and M. Gleichenhagen, Food Chemistry, 124, 1543(2011), DOI: 10.1016/j.foodchem.2010.08.009.

12. S. Shiyan, T. Hertiani, R. Martien and A. K. Nugroho, International Journal of Applied Pharmaceutics, 259(2018), DOI: 10.22159/ijap.2018v10i6.29654.

13. C. Henríquez, S. Almonacid, I. Chiffelle, T. Valenzuela, M. Araya, L. Cabezas, R. Simpson and H. Speisky, Chilean Journal of Agricultural Research, 70, 523(2010), DOI: 10.4067/S071858392010000400001.

14. G. Pratiwi, R. Martien and R. Murwanti, International Journal of Applied Pharmaceutics, 11, 50(2019), DOI: 10.22159/ijap.2019v11i2.29999.

15 C. Lantano, M. Rinaldi, A. Cavazza, D. Barbanti and C. Corradini, Journal of Food Science and Technology, 52, 8276(2015), DOI: 10.1007/s13197-015-1971-4.

16 G. C. Tenore, P. Stiuso, P. Campiglia and E. Novellino, Food Chemistry, 141, 2379(2013), DOI: 10.1016/j.foodchem.2013.04.128.

17 H. Xu, Protein and Peptide Letters, 17, 1270(2010), DOI: 10.2174/092986610792231492.

[RJC-5755/2020] 